\title{
Mental healthcare reform in the Republic of Moldova
}

\section{Martin Zinkler, ${ }^{1}$ Larisa Boderscova ${ }^{2}$ and Jana Chihai ${ }^{3}$}

\author{
${ }^{1}$ Consultant Psychiatrist, East London NHS Foundation Trust, Newham Centre for Mental Health, Cherry Tree Way, Glen Road, \\ London E13 8SP, UK, email martin.zinkler@eastlondon.nhs.uk; \\ ${ }^{2}$ Country Project Manager, Stability Pact Mental Health Project 'Strengthening Social Cohesion Through the Fortification of Community \\ Mental Health Services in South-East Europe', Chisinau, Republic of Moldova \\ ${ }^{3}$ Director of the Community Mental Health Centre, President, SOMATO, Psychiatrist-Psychotherapist, Balti, Republic of Moldova
}

$\mathrm{M}$ ental healthcare in the countries of the former Soviet Union faces considerable challenges as result of the socio-economic transition. In this article we look at the changes in the Republic of Moldova. We identify weaknesses and strengths in the traditional hospital-based system and describe examples of the successful implementation of modern mental health services. We follow the reform process in mental health law and service provision in view of the recommendations from the Council of Europe (2004) for the protection of human rights of persons with mental disorder. Some of the information in this article was gathered during official visits to mental healthcare institutions in the Republic of Moldova in 2006.

The Republic of Moldova lies between Romania to the west and Ukraine to the east and south. Formerly part of the Soviet Union, it became independent in 1991. It is a densely populated country, with just under 3.4 million people in an area the size of Belgium. It has one of the lowest per capita gross domestic products in Europe, at US\$2374.

Mental health in Moldova has deteriorated since the breakdown of the USSR, with the emergence of severe social and economic problems. In particular, the rates of alcohol and drug misuse and of domestic violence have increased. At the same time, services have also deteriorated. There are now fewer psychiatric beds and fewer out-patient consultations than in the Soviet era. Table 1 gives some statistics comparing present provision in Moldova with that elsewhere in Europe.

Three large psychiatric hospitals in Moldova provide inpatient and out-patient treatment. Encounters with this system do not cover all needs and may result in long-term stigmatisation because of the compulsory registration procedures, the subsequent limitations on the right to practise certain types of professional activities or long-term hospitalisation. After patients have been discharged, their families carry the financial and moral burden in the community. Psychiatrists and nurses dominate the workforce, as the emphasis is on a biomedical model.

\section{Transition from hospital-based care to community care}

The psychiatric hospital of Chisinau, the largest in the country, currently has 1200 beds, for a population of about 2 million people. It used to house 2000 beds. Many of the
Table 1 Comparative statistics for Moldovan service provision

$\begin{array}{lrrc} & \text { Moldova } & \text { Europe } & \text { UK } \\ \text { Psychiatrists/100 000 population } & 9.0 & 9.0 & 11 \\ \text { Psychiatric nurses/100 000 population } & 30.5 & 27.5 & 104 \\ \text { Psychologists/100 000 population } & 0.7 & 3.0 & 9.0 \\ \text { Social workers/100 000 population } & 0.5 & 2.35 & 58 \\ \text { Psychiatric beds/10000 population } & 6.7 & 8.7 & 5.8 \\ \text { \% of health budget spent on } & 6.5 & 5.8 & 10.0 \\ \quad \text { mental health } & & & \\ \text { \% of GDP spent on health } & 3.6 & 9.0 & 7.7\end{array}$

Source: World Health Organization (2001).

old hospital buildings (from 1895) were destroyed by an earthquake in 1976. The hospital operates an out-patient department where 400 patients are seen per day, mainly by doctors. Some of the patients are on community treatment orders; most, though, attend voluntarily. The in-patient department is organised in a traditional asylum style, with acute locked wards for men, acute locked wards for women and mixed open wards for male and female 'neurotic' patients. There are about 70 patients per ward, in bedrooms for up to 12 patients. About $10 \%$ of patients on the acute wards are on detention orders. Mental healthcare in hospital (in-patient and out-patient) is provided free of charge. Even by Moldovan standards, trained psychiatrists have very low salaries - around US\$50 a month. In recent years, hardly any doctors trained to become psychiatrists; most young doctors left the country to work abroad. Generally, when a psychiatrist resigned, the post remained vacant.

More than 2500 Moldovan citizens with long-term mental health problems live in traditional long-term institutions, socalled psycho-neurological institutions or social care homes, funded by social budgets and local municipalities. The steady increase in the number of people in these institutions since independence is widely interpreted as resulting from socioeconomic stress, particularly for vulnerable people, during the transition from socialism to a free-market economy. For many people, the institution saves them from homelessness.

The social care home of Balti, for example, situated in the north of Moldova, accommodates 550 people. A third of the residents are over 65 years of age. People are institutionalised because of mental disabilities, intellectual disabilities or simply because no one looks after them. There are no daytime activities for residents. The director of that home explained that 'people here entertain themselves'. 
Some wards are locked, while others are open; residents on locked wards have no personal possessions at all. A retired cleaner still attends 'her ward' every day because no one else would speak to the residents and she regards them as 'her children'. To get discharged, residents have to prove that someone will look after them. The institution does not employ any social workers who could facilitate a rehabilitation or discharge process.

Joint action by the Council of Europe and the World Health Organization's Regional Office for Europe in 2001 created the Health Network for South-Eastern Europe. The basis for this was the information on access to healthcare for the vulnerable population from the region. In September 2001, the 'Dubrovnik Pledge' was signed to protect vulnerable populations in south-eastern Europe and, through this, to contribute to peace, development, democratisation, stability and reconciliation. Medical assistance was introduced into the Stability Pact Initiative for Social Cohesion (http://www. stabilitypact.org). The objective was to develop community mental health services by amending mental health legislation to comply with European standards, by establishing a model for community mental health services, and by establishing a region-wide network for training and collaboration in community mental health, primary care and social work.

The first state-run community mental health centre in Moldova was created with financial support from the Greek government. The centre still has to become fully operational, however; difficulties arise from the fact that only the building and equipment were funded by the South-Eastern Europe Stability Pact, while operational costs and personnel will have to be paid by the national government. The community centre, when fully staffed, will provide assessment, treatment (including medication and psychotherapy), psychosocial support and legal advice free of charge for the 120000 inhabitants of the capital. There are currently no other state-run community mental health centres in the capital or indeed elsewhere.

\section{Mental healthcare in primary care settings}

In 2000, Moldova started the transition to a health service based upon primary care, and 35\% of the health budget is now spent on primary care. There are now 2100 doctors working in primary care, each serving populations of 1000 2000; some previously worked as specialists such as internal physicians and psychiatrists. A new 3-year specialist training course in family medicine has been implemented, which includes 140 hours of training in mental healthcare. Primary care workers, such as nurses, go through internship programmes that include mental health. Guidelines for the treatment of depression in primary care are being developed.

\section{Non-governmental organisations}

Moldova Philantropie, in Chisinau, was founded in 2000 and provides a rehabilitation programme for 25-40 people, close to the city centre. Funding ended in April 2003 and the centre is struggling to continue with its activities, which include social events, art, English lessons, information, mental health and legal advocacy and psychotherapy. The centre operates like a club; membership and services are free of charge and it has now developed into a service user organisation, the first of its kind in Moldova.

A community mental health centre called Somato, in Balti, $135 \mathrm{~km}$ north of Chisinau, was also founded in 2000, with funds from the Soros Foundation and other organisations. Its director used to work as a psychiatrist at the nearby social care home (described above) and has managed to set up a comprehensive community-oriented mental health project with close links to the local administration and the local population. Situated in a two-storey house in a residential neighbourhood, the centre provides assessment, treatment, daytime activities and respite care (short-term admission) for people aged 14 years and older. Service users are involved in running the service, maintaining the building and engaging in mental health promotion activities, but they also receive psychotherapy, occupational therapy, art therapy, advocacy and meals, 7 days per week. Medication is prescribed, but it has to be paid for by the service users themselves. In December 2004, this centre was donated to the local public administration (LPA), Balti municipality. Through a memorandum of understanding between Somato and the LPA, this centre now has dual control (i.e. between Somato and the LPA). It is still quite complicated to integrate this type of service into the present healthcare structure.

\section{Legal reform}

Moldova has a relatively new mental health law (Law Regarding the Rendering of Psychiatric Care, number 1402-XII, of 16 December 1997). People with mental disorders have all the rights and freedom of citizens stipulated by the Moldovan constitution and other laws. Restrictions are allowable only in cases provided by the present law and other statutory acts.

A person with a mental disorder may be detained in a psychiatric hospital without consent or without the consent of a lawful representative (assigned by the court) if examination or treatment is possible only in hospital, and the mental disorder is severe and causes:

o direct danger to the patient or to associates

$O$ an inability to satisfy personal basic vital needs

O essential harm to health if psychiatric help is not rendered.

The criteria for involuntary treatment are the same as those above for involuntary admission (danger, inability to satisfy basic vital needs, essential harm). A judge must authorise involuntary admission within 3 days. The patient, a lawful representative, the head of the psychiatric hospital and the public prosecutor all have the right to appeal against the decision of the court for involuntary admission. The involuntary patient has to be reviewed no less than once a month by a commission of psychiatrists. After 6 months, the decision goes back to the judge. Thereafter, a judicial review is conducted annually. In-patient psychiatric care has to be provided under the least restrictive conditions that will ensure the safety of the hospitalised person and other persons.

Moldovan mental health law is mostly compliant with the latest recommendations from the Council of Europe (2004). However, there is no requirement for a written care plan and 
the conditions for involuntary placement and treatment do not include a therapeutic purpose. The law does not provide free legal representation for detained patients. The legal situation of people in social care homes remains largely unclear, as they are de facto detained but without the requirement for judicial reviews or other legal safeguards. A major concern for non-governmental organisations is that the new law has not been fully implemented.

\section{References}

Council of Europe (2004) Recommendation No. Rec(2004)10 of the Committee of Ministers to member states concerning the protection of the human rights and dignity of persons with mental disorder and its explanatory memorandum. See https://wcd.coe.int/ViewDoc. jsp?id=775685 (last accessed November 2008).

World Health Organization (2001) Atlas - Country Profiles on Mental Health Resources 2001. WHO.

\title{
The organisation of mental health services in post-war Bosnia and Herzegovina
}

\section{Osman Sinanovic, ${ }^{1}$ Esmina Avdibegovic, ${ }^{2}$ Mevludin Hasanovic, ${ }^{2}$ Izet Pajevic, ${ }^{2}$ Alija Sutovic, ${ }^{2}$ Slobodan Loga ${ }^{3}$ and Ismet Ceric ${ }^{3}$}

\begin{abstract}
1Department of Neurology and 'Department of Psychiatry, University Clinical Centre Tuzla, Medical Faculty, University of Tuzla, 75000 Tuzla, Bosnia and Herzegovina; ${ }^{3}$ Department of Psychiatry, Clinical Hospital Centre Sarajevo, Medical Faculty, University of Sarajevo, 71000 Sarajevo, Bosnia and Herzegovina
\end{abstract}

$B^{\circ}$ osnia and Herzegovina $(\mathrm{BH})$ is located on the western part of the Balkan Peninsula. It has an area of $51210 \mathrm{~km}^{2}$ and a population of 3972000 . According to the Dayton Agreement of November 1995, which ended the 1992-95 war, BH comprises two 'entities' - the Federation of Bosnia and Herzegovina (FBH) and the Republic of Srpska (RS) - and the District of Brcko. The administrative arrangements for the management and financing of mental health services reflect this. The FBH, with 2325018 residents, is a federation of 10 cantons, which have equal rights and responsibilities. The RS has 1487785 residents and, in contrast, a centralised administration. Brcko District has just under 80000 residents.

\section{Mental health policy and legislation}

Healthcare systems in $\mathrm{BH}$ are regulated basically by the entities' different laws on healthcare and on health insurance. Each entity and Brcko District is responsible for the financing, management, organisation and provision of healthcare. The health administration is centralised in RS, through the Ministry of Health and Social Welfare, but in $\mathrm{FBH}$ is decentralised - each of the 10 cantonal administrations has responsibility for healthcare through its own ministries. The central Ministry of Health of the FBH, located in Sarajevo, coordinates cantonal health administrations at a federal level. The District of Brcko provides primary and secondary care to its citizens. The mental health policies and national programmes for mental health were created in 1999 and adopted in 2005. A law on the protection of persons with mental disorders was adopted in 2001 and 2002 in FBH (Official Gazette of BH, Nos 37/01 and 40/02), and in 2004 in RS (Official Gazette of RS, No. 46/04). These laws define the rights of people and regulates the procedure for voluntary or involuntary admission to a psychiatric hospital.

\section{Mental health service delivery}

There are no private mental health institutions. Psychiatric services are available for all citizens, paid from a special national fund for healthcare, financed by mandatory health insurance. The reform of mental health services began in 1995. The focus has been on care in the community, limiting the use of psychiatric hospital beds, establishing a network of community mental health centres (CMHCs), and developing other services in the community, a multidisciplinary approach and teamwork, as well as cooperation between sectors. Each $\mathrm{CMHC}$ is responsible for general mental health in a catchment area of 50000-80000 inhabitants; each has 10 psychiatric beds, intended for the acute admission of patients (these beds are in fact on neuropsychiatric wards of regional general hospitals). The CMHCs have many different functions, including the promotion of mental health, early detection of mental disorders, and the provision of multidisciplinary care (Ceric et al, 2001).

Psychiatric services are provided throughout $\mathrm{BH}$ through the network of $55 \mathrm{CMHCs}$ and family medicine services at primary care level. Secondary and tertiary mental health services are provided in three psychiatric clinics, one department of a university clinical centre, two general psychiatry hospitals, two institutions for the treatment, rehabilitation and social care of patients who are chronically mentally ill, and neuropsychiatric wards in general hospitals in major cities. In the reform of the mental health services, mentioned above, new out-patient services were established, the existing 